\title{
PERBANDINGAN LATIHAN KOTAK BERWARNA DENGAN SEGI TIGA ANGKA TERHADAP PASSING ATAS BOLA VOLI
}

\author{
Boby Agustan \\ STKIP Muhammadiyah Kuningan \\ email: bobyagustan@gmail.com
}

\begin{abstract}
Abstrak
Bentuk latihan yang diciptakan ada yang menggunakan alat, media, atau tanpa alat. Peneliti dalam kesempatan ini mencoba dua bentuk latihan yang menggunakan alat atau media. Media tersebut adalah kotak dan segi tiga. Kotak dan segi tiga tersebut diberi tanda. Tanda yang dimaksud penulis dapat berupa angka, huruf, atau warna. Tujuan dari tanda tersebut adalah untuk mengatur ke arah mana pemain pada saat melakukan passing atas. Metode eksperimen yang digunakan dalam penelitian ini, populasi adalah siswa putera SMA Negeri 1 Cikatomas sebanyak 20 siswa putera. Sampel penelitian yang digunakan dalam penelitian ini adalah sampel total atau seluruh populasi dijadikan sampel penelitian yaitu sebanyak 20 siswa putera. Sampel setelah diberikan perlakukan dengan antara latihan kotak berwarna dan segi tiga angka. Adapun kesimpulan dari penelitian yang penulis lakukan adalah sebagai berikut: 1) Latihan media kotak berwarna memberikan pengaruh yang signifikan terhadap peningkatan passing atas dalam permainan bola voli; 2) Latihan media segi tiga angka memberikan pengaruh yang signifikan terhadap peningkatan passing atas dalam permainan bola voli; dan 3) Latihan kotak berwarna memberikan pengaruh yang lebih signifikan terhadap peningkatan passing atas dalam permainan bola voli dibandingkan dengan segi tiga angka.
\end{abstract}

Kata Kunci: Latihan, Kotak Berwarna, Segitiga Angka, Passing Atas, bola voli

\begin{abstract}
Forms of training that are created there are using tools, media, or without tools. Researchers in this opportunity try two forms of exercise that use tools or media. The media are boxes and triangles. The box and triangle are marked. The author's intended mark may be a number, letter, or color. The purpose of the sign is to set in which direction the player is at the time of passing up. The experimental method used in this study, the population is the students of SMA Negeri 1 Cikatomas son as many as 20 students of the son. The sample of research used in this study is the total sample or the entire population used as a sample of research that is as many as 20 students son. The sample after being treated with between the colored box and triangular exercise. The conclusions of the research that the authors do is as follows: 1) Color box color exercise to give a significant effect on the increase of passing up in the game of volleyball; 2) The triangular media exercise gives a significant effect on the increase of the upper passing in the game of volleyball; And 3) Colored box exercises have a more
\end{abstract}


significant effect on increasing the upper passing in the game of volleyball than the triangle.

Keywords: Color Box, Exercises, Triangle Numbers, Passing Up, Volley Ball.

(C) 2017 STKIP Muhammadiyah Kuningan 


\section{PENDAHULUAN}

Latihan merupakan sebuah proses yang harus dilakukan oleh setiap atlet apabila ingin menambah kemampuannya. Proses latihan inilah yang sangat vital dalam mencapai tujuan olahraga. Harsono (1988:102) berpendapat bahwa "Latihan adalah proses kerja yang dilakukan dengan sistematis, kontinyu di mana beban dan intensitas latihan makin hari makin bertambah, yang pada akhirnya memberikan rangsangan secara menyeluruh terhadap tubuh dan bertujuan untuk meningkatkan kemampuan fisik dan mental secara bersama-sama".

Latihan yang sistematis adalah program latihan direncanakan secara matang dilaksanakan sesuai jadwal menurut pola yang telah ditetapkan, dan dievaluasi sesuai dengan alat yang benar. Penyajian materi harus dilaksanakan dari materi yang paling mudah ke arah materi yang paling sukar, dari materi yang sederhana mengarah kepada materi yang paling kompleks. Latihan harus dilakukan secara berulang-ulang, maksudnya latihan harus dilakukan minimal tiga kali dalam seminggu. Pengulangan ini diharapkan gerakan yang pada saat awal latihan dirasakan sukar dilakukan, pada tahaptahap berikutnya akan menjadi lebih mudah dilakukan, tambahan beban jumlah beban harus dilakukan pada setiap kali latihan dan tambahan beban ini segara dilakukan ketika atlit merasakan bahwa latihan yang dilaksanakan terasa ringan, latihan tersebut dimaksud untuk membantu meningkatkan keterampilan dan prestasi atlit semaksimal mungkin. Menurut pendapat Harsono (1988:100) sebagai berikut: Terdapat empat aspek yang harus diperhatikan dan latihan atlit yaitu: 1) Latihan fisik (physical training), 2) Latihan Teknik (technical training), 3) Latihan Taktik, 4) Latihan Mental.

Latihan ini harus dilakukan untuk menunjang kemampuan fisik, teknik dan taktik. Empat komponen ini merupakan satu kesatuan yang utuh sehingga harus ditingkatkan secara bersama-sama untuk menunjang prestasi atlit baik dari segi fisik yang kuat melalui penambahan beban latihan, teknik tinggi melalui inovasi kemampuan individual, taktik tepat untuk mensiasati lawan, dan mental yang kuat bermanfaat sebagai penopang kesemuanya. Keempat aspek tadi fokuskan kepada latihan teknik dan taktik dalam pemahaman yang cukup dominant untuk meningkatkan prestasi bermain yang tinggi dalam bola voli, yang menjadi persaratan mutlak bagi para pemain penguasaan teknik dan taktik ini, karena sudah pasti akan dikenakan hukuman oleh wasit yang cukup berat dengan angka untuk lawan dalam sistem reli poin, jika pemain kesalahan dalam teknik ataupun taktik, membawa implikasi terhadap proses pembinaan prestasi bola voli, mereka harus dibina agar kualitas teknik dan taktiknya 
prima sesuai dengan peraturan yang berlaku.

Teknik dalam permainan bola voli salah salah satunya passing atas. Passing atas ini merupakan salah satu teknik yang berguna dan penunjang dalam menciptakan sebuah spike. Passing atas lebih terkontrol, akurat, dan lebih cepat pantulan yang dihasilkannya pada saat pemain akan melakukan spike. Pengalaman penulis di lapangan, sebuah tim akan tampak menyatu atau kerjasamanya bagus tergantung dari pengumpan. Pengumpan itu sendiri banyak melakukan passing dengan passing atas. Teknik dasar yang lain, bukan berarti tidak perlu dilatih tetapi dominan melakukan passing atas pada saat mengumpan kepada pemain yang akan spike.

Berdasarkan hal tersebut, maka perlu dilatih lebih teknik passing atas ini, agar lebih terampil dalam bermain bola voli. Banyak bentuk latihan yang dilakukan dalam melatih passing atas. Bentuk-bentuk latihan tersebut bertujuan untuk variasi latihan, tergantung tujuan, dan dalam rangka agar pemain tidak merasakan jenuh saat latihan. Bentuk latihan yang diciptakan ada yang menggunakan alat, media, atau tanpa alat. Penlulis dalam kesempatan ini mencoba dua bentuk latihan yang menggunakan alat atau media. Media tersebut adalah kotak dan segi tiga. Kotak dan segi tiga tersebut diberi tanda. Tanda yang dimaksud penulis dapat berupa angka, huruf, atau warna. Tujuan dari tanda tersebut adalah untuk mengatur ke arah mana pemain pada saat melakukan passing atas.

Mengacu kepada paparan tersebut, penulis mencoba mengajukan penelitian dengan judul "Perbandingan Latihan Kotak Berwarna dengan Segi Tiga Angka terhadap Peningkatan Passing Atas dalam Permainan Bola Voli”.

\section{METODE}

Metode yang digunakan dalam penelitian ini adalah metode eksperimen. Populasi dalam penelitian ini adalah siswa putera SMA Negeri 1 Cikatomas sebanyak 20 siswa putera. Sampel penelitian yang digunakan dalam penelitian ini adalah sampel total atau seluruh populasi dijadikan sampel penelitian yaitu sebanyak 20 siswa putera. Desain penelitian ekspermen ini menggunakan desain "Pretest-posttest design". Instrumen tes yang digunakan dalam penelitian adalah tes passing atas yang mengacu kepada buku tes dan pengukuran karangan Nurhasan.

\section{HASIL PENELITIAN}

Data yang diperoleh melalui tes awal dan tes akhir belum begitu berarti dan masih merupakan skor-skor mentah. Untuk mendapatkan kesimpulan serta arti dan makna dari data-data tersebut, selanjutnya penulis olah dengan melakukan pengukuran dan analisis secara statistika. Pengolahan dan analisis data dalam penelitian ini berdasarkan kepada langkah-langkah 
penelitian yang telah penulis susun sebelumnya. Adapun hasil pengolahan dan analisis data tersebut penulis uraikan pada tabel-tabel di bawah ini:

Tabel 1 Hasil Penghitungan Nilai Rata-Rata dan Simpangan Baku Kelompok Penelitian

\begin{tabular}{|c|c|c|c|c|}
\hline \multirow{2}{*}{ Kelompok Penelitian } & \multicolumn{2}{|c|}{$\begin{array}{c}\text { Sebelum } \\
\text { Eksperimen }\end{array}$} & \multicolumn{2}{c|}{$\begin{array}{c}\text { Sesudah } \\
\text { Eksperimen }\end{array}$} \\
\cline { 2 - 5 } & $\overline{\mathrm{X}}$ & $\mathrm{S}$ & $\overline{\mathrm{X}}$ & $\mathrm{S}$ \\
\hline (A) Latihan kotak berwarna & 9.80 & 12.60 & 2.53 & 1.84 \\
\hline (B) Latihan segi tiga angka & 9.70 & 11.30 & 2.11 & 1.64 \\
\hline
\end{tabular}

Kriteria pengujian homogenitas dua kelompok sampel tersebut di atas adalah terima hipotesis Ho jika, $\mathrm{F}(1-\alpha)(\mathrm{n}-1)<\mathrm{F}<$ F 1/2 $\alpha(\mathrm{n} 1-1, \mathrm{n} 2-1)$, dan tolak Ho, apabila F $>$ F $1 / 2 \alpha(\mathrm{V} 1, \mathrm{~V} 2)$. Berdasarkan kepada hasil pengolahan dan analisis data variabel penelitian, maka diketahui nilai F-hitung untuk kelompok A (latihan kotak berwarna ) sebesar 1.89, dan kelompok B (latihan segi tiga angka) sebesar 1.66, nilai tersebut menunjukkan tingkat homogen, hal ini dikarenakan nilai tersebut berada di bawah nilai $\mathrm{F}$-tabel dengan $\mathrm{dk}=(\mathrm{n}-1, \mathrm{n}-1)$ pada taraf nyata $\alpha=0.05$ (nilai F-tabel $=3.18$ ) dengan demikian hasil pengujian kesamaan dua variansi tersebut menunjukkan distribusi data yang homogen.

Langkah selanjutnya adalah melakukan pengujian normalitas dengan menggunakan uji kenormalan liliefors. Adapun hasil penghitungan normalitas kedua kelompok dapat dilihat dalam tabel 4.3 di bawah ini:

Tabel 2

Hasil Uji Normalitas Kelompok Penelitian

\begin{tabular}{|c|c|c|c|c|}
\hline \multirow{2}{*}{ Kelompok Penelitian } & \multicolumn{2}{|c|}{$\begin{array}{c}\text { Nilai Lo } \\
\text { Periode Tes }\end{array}$} & \multirow{2}{*}{$\begin{array}{c}\text { Nilai } \\
\text { L-Tabel }\end{array}$} & \multirow[b]{2}{*}{ Kesimpulan } \\
\hline & wal $^{\mathbf{A}}$ & Akhir & & \\
\hline \multirow[t]{2}{*}{ (A) Latihan kotak berwarna } & $612^{0.1}$ & 0.2078 & 0.2580 & Normal \\
\hline & 0.1910 & 0.1852 & 0.2580 & Normal \\
\hline
\end{tabular}




\begin{tabular}{|l|l|l|l|l|}
\hline (B) Latihan segi tiga angka & & & & \\
\end{tabular}

Berdasarkan hasil penghitungan di atas didapat nilai-nilai Lo yang berada di bawah nilai L-tabel, dimana untuk variable latihan kotak berwarna memiliki nilai tes awal dan akhir sebesar (0.1612) dan (0.2078), sedangkan untuk latihan segi tiga angka memiliki nilai tes awal dan akhir sebesar (0.1910) dan (0.1852). Semua nilainilai tersebut berada di bawah nilai t-tabel untuk $\mathrm{n}=10$ dengan $\alpha=0.05$ yaitu sebesar (0.258). Dengan demikian populasi tersebut mempunyai nilai kenormalan, selanjutnya pengujian dilakukan dengan penghitungan parametrik.

Langkah pengujian selanjutnya adalah pengujian dan analisis rata-rata, hal ini dilakukan untuk mengetahui apakah terdapat peningkatan hasil latihan dari kedua kelompok penelitian setelah mendapatkan treatmen latihan selama enam minggu, sehingga hasil yang didapat apakah signifikan atau tidak signifikan.

Adapun hasil analisis dan penghitungannya dapat dilihat pada tabel penghitungan di bawah ini.

Berdasarkan pada penghitungan dan analisis nilai t-hitung yang diperoleh, maka didapat nilai t-hitung yang lebih besar dari $\mathrm{t}$-tabel pada tingkat kepercayaan atau taraf nyata $\alpha=0.05$ dengan $\mathrm{dk}(\mathrm{n} 1+\mathrm{n} 2-2)=$ 18, dimana harga $t(1-1 / 2 \alpha)$, dalam daftar distribusi diperoleh harga $t$-tabel sebesar
2.23. Dikarenakan hasil t-hitung lebih besar dari nilai t-tabel yaitu (7.40), maka pengujian tersebut signifikan dan hasilnya adalah tidak terdapat perbedaan pengaruh, artinya kedua kelompok tersebut samasama memberikan pengaruh terhadap keterampilan passing atas dalam permainan bola voli di SMA Negeri 1 Cikatomas.

\section{SIMPULAN}

Berdasarkan pada pembahasan babbab sebelumnya yaitu mulai dari pemaparan latar belakang masalah, perumusan penelitian, serta pengajuan hipotesis. Kemudian pemahaman pada kajian teori, penerapan metode penelitian, serta pengolahan data dengan analisis penghutungan statistik, maka dalam penelitian ini penulis menemukan jawaban sebagai akhir dari penelitian yang penulis lakukan.

Selanjutnya beberapa jawaban yang ada, penulis rumuskan dalam bab kesimpulan sebagai akhir dari penelitian yang telah dilakukan. Adapun beberapa kesimpulan penelitian tersebut di antaranya adalah sebagai berikut:

1. Latihan media kotak berwarna memberikan pengaruh yang signifikan terhadap peningkatan passing atas dalam permainan bola voli.

2. Latihan media segi tiga angka memberikan pengaruh yang signifikan 
terhadap peningkatan passing atas dalam permainan bola voli.

3. Latihan kotak berwarna memberikan pengaruh yang lebih signifikan terhadap peningkatan passing atas dalam permainan bola voli dibandingkan dengan segi tiga angka.

\section{DAFTAR PUSTAKA}

Amatembun. (1993), Administrasi

Pendidikan. Bandung: FIP IKIP Bandung.

Arikunto, Suharsimi (2010). Prosedur Penelitian Suatu Pendekatan Praktek. Rineka Cipta, Jakarta.

Bachtiar, N. 2003. "Manajemen Pembelajaran di Sekolah". Jakarta : Gramedia.

Harsono, (1988), Coaching dan AspekAspek Psikologis dalam Coaching,

Kurniawan, K., \& Ramadan, G. (2016). Pengaruh Latihan Plyometric Terhadap Hasil Smash Pada Ekstrakurikuler Bolavoli. JUARA : Jurnal Olahraga, 1(2), 110-120. Retrieved from http://jurnal.upmk.ac.id/index.php/j uara/article/view/25

Mamung Amung, Subroto Toto. (2001).
Pendekatan Keterampilan Teknis dalam Permainan Bola Voli. Jakarta: Dirjen Dikdasmen Olahraga

Nasution (1987). Metode Penelitian. UGM Yogyakarta.

Nurhasan, 2001. Tes dan Pengukuran Dalam Pendidikan Jasmani, Direktorat Jenderal Olahraga Depdiknas, Jakarta.

Suharno, (1979), Dasar-dasar Bermain Bola Voli dan Peraturannya, Bandung: FPOK IKIP Bandung.

Sukintaka. (1992). Teori bermain penjaskes. Jakarta

Sugiyono, 2009. Statistika untuk Penelitian. CV. Alfabeta, Bandung.

Sudjana. (1992). Statistik. Bandung. Tarsito

Supandi, K (1991), Manajemen Pendidikan Jasmani dan Olahraga. Diktat. Bandung: FPOK Bandung.

Surahman, (1982), Penelitian pendidikan, Jakarta : BPK Gunung Mulia.

Viera, Barbara L, dan Ferguson, Bonnie, Jill (1996). Bola Voli Tingkat Pemula. Terj. Monti. Raja Grafindo Persada : Jakarta. 